\title{
СРАВНИТЕЛЬНЫЙ АНАЛИЗ ПОКАЗАТЕЛЕЙ ГЛИКИРОВАННОГО ГЕМОГЛОБИНА У ДЕТЕЙ И ПОДРОСТКОВ С САХАРНЫМ ДИАБЕТОМ 1 ТИПА, ПОЛУЧАЮЩИХ ТЕРАПИЮ МЕТОДОМ ПОСТОЯННОЙ ПОДКОЖНОЙ ИНФУЗИИ ИНСУЛИНА, С НЕПРЕРЫВНЫМ МОНИТОРИНГОМ ГЛИКЕМИИ И БЕЗ НЕГО
}

\author{
Ладина И.И.
}

ГАУЗ ТО «Городская поликлиника №5», Тюмень

ЦЕЛЬ: оценить вклад использования приборов для непрерывного мониторинга гликемии в достижение целевых значений углеводного обмена у детей, получающих терапию методом постоянной подкожной инфУзии инсУлина.

МАТЕРИАЛЫ И МЕТОДЫ: объект исследования: 30 детей с сахарным диабетом 1 типа, получающих инсулинотерапию с помощью инсулиновых помп фирм Roshe и Medtronik. Bce пациенты ежедневно проводили самоконтроль гликемии с помощью глюкометра. Стаж сахарного диабета на момент проведения оценки каждого из исследуемых более 1 года, помповая инсулинотерапия в течение более, чем 6 месяцев. Все пациенты находились под амбулаторным наблюдением детского эндокринолога поликлиники.

Пациенты были разделены на группы по критериям наличия и отсутствия приборов для непрерывного мониторинга гликемии FreeStyle Libre. Количество детей в группе, использующей прибор для непрерывного мониторинга гликемии FreeStyle Libre (1 группа) и в группе пациентов без непрерывного мониторинга гликемии (2 группа)- по 15 человек. Возраст пациентов на момент исследования: в 1 группе от 4 лет до 17 лет (средний возраст 11 лет, $\sigma=4,13)$, во 2 группе от 5 лет до 16 лет (средний возраст 13 лет, $\sigma=3.44$ ). Производилась сравнительная оценка показателей гликированного гемоглобина у детей с сахарным диабетом 1 типа, получающих терапию методом постоянной подкожной инфузии инсулина, с непрерывным мониторингом гликемии и без него, путем подсчета среднего значения и стандартного отклонения (б) в каждой группе.

PЕЗУЛЬТАТЫ: показатели гликированного гемоглобина в 1 группе варьировали от 5,9\% до 7,6\% (средний уровень $\left.\mathrm{HbA}_{1 c} 6,7 \%, \sigma=0,63\right)$. Показатели гликированного гемоглобина в 1 группе варьировали от 6,5\% до 10,0\% (средний уровень $\mathrm{HbA}_{1 с} 8,89 \%, \sigma=1,29$ ).

\section{ВЫводы:}

1. По данным проведенного исследования, все пациенты в группе, использующей устройства для непрерывного мониторинга гликемии, находились в состоянии компенсации и субкомпенсации сахарного диабета 1 типа, тогда как большинство пациентов из группы, использующей для самоконтроля лишь индивидуальные глюкометры, выходили из пределов целевого значения гликированного гемоглобина. Полученные данные доказывают значимость проведения непрерывного мониторинга гликемии детям с сахарным диабетом 1 типа.

2. Также, возможно, использование систем для непрерывного мониторинга гликемии повышает комплаентность пациента за счет отражения большего числа показателей гликемии в течение дня по сравнению с использованием индивидуального глюкометра. 